\title{
Intertrial interval shift and avoidance behavior in fish ${ }^{12}$
}

GeORGe A. PINCKNEY

STATE UNIVERSITY OF NEW YORK COLLECE AT BROC'KPORT

The possibility that length of intertrial interval serves a reinforcement function was investigated by shifting ITI for two groups of fish, while holding ITI constant for their controls. ITI shift resulted in performance changes which could not be accounted for by either a reinforcement or a distribution of practice hypothesis. The pos sibility that a generalization decrement led to the changes was suggested.

The results of research on the effect of intertrial interval (ITI) length on performance in shuttlebox avoidance learning have consistently shown that learning is facilitated by longer ITIs (Murphy \& Miller, 1956; Brush, 1962; Pinckney, 1966). Less clear, however, is the reason for this. Two points of view prevail: the distribution of practice view and the reinforcement view. The distribution of practice argument holds that increasing ITI constitutes a spacing of practice, and thus leads to enhanced performance. The reinforcement view, on the other hand, holds that fear can be reduced to a greater extent when responses are followed by longer ITIs than it can when responses are followed by relatively short ITIs.

The present study was designed to investigate the possibility that the ITI serves a reinforcement function; that is, that longer ITIs allow more fear to be reduced. If longer intervals provide for more reinforcement, then they serve a quantity of reinforcement or incentive function. This possibility could best be tested, it seemed, by employing the incentive shift model developed by Crespi (1944), Zeaman (1949), and others.

\section{Method}

Ss for this study were 56 adult Mexican swordtails (Xiphophorus helleri), averaging $2-1 / 2$ in. in length, exclusive of the tails of the males. They were housed in individual 2-1/2 gallon tanks which were heated and continuously aerated. Water temperature was maintained at $72-74^{\circ} \mathrm{F}$, and the $\mathrm{pH}$ level was 7.0.

Avoidance conditioning took place in an aquatic shuttlebox described in detail by Pinckney (1966). Training consisted of six daily sessions of 20 trials each. A delayed conditioning procedure was used, with a 10 sec CS-US interval and a 5 sec shock period. A trial was initiated by the onset of a light at the end of the compartment occupied by $S$. A response to this $\mathrm{CS}$ alone terminated the light and allowed $\mathrm{S}$ to avoid the shock completely, while a response during the $5 \mathrm{sec}$ shock period terminated both the CS and the US. Both the CS and US were terminated automatically at the end of $15 \mathrm{sec}$ on those trials where $S$ failed to respond.
On the first three days, one half the Ss were trained with a $5 \mathrm{~min}$ ITI, while the other half were trained with a 30 sec ITI. On Days 4-6, one half the Ss trained with the $5 \mathrm{~min}$ ITI continued with the 5 min interval (Group 5-5), while the other half were shifted to the $30 \mathrm{sec}$ ITI (Group 5-30). In addition, one half the Ss trained with the $30 \mathrm{sec}$ ITI were shifted to the $5 \mathrm{~min}$ interval (Group 30-5), while the other half continued with the 30 sec ITI (Group 30-30). Each pair of groups was matched on the number of avoidances made during the three session prior to the shift in ITIs. Results

Available for analysis were the number of avoidances made by each $S$ on each day of the experiment, as well as the latencies of the responses. The mean number of avoidances made by Ss in each of the four groups are shown in Fig. 1. These data were subjected to an analysis of variance with the main effects of shift $(\mathrm{F}=110.25, \mathrm{df}=1 / 156, \mathrm{p}<.001)$, days $(\mathrm{F}=28.43$, $\mathrm{df}=2 / 104, \mathrm{p}<.001)$, and groups $(\mathrm{F}=3.02, \mathrm{df}=3 / 52$, $\mathrm{p}<.01)$ all found to be significant. All interactions, except shift by days, were also significant.

Individual $t$ tests indicated that the two groups trained with the 5 min ITI made significantly more

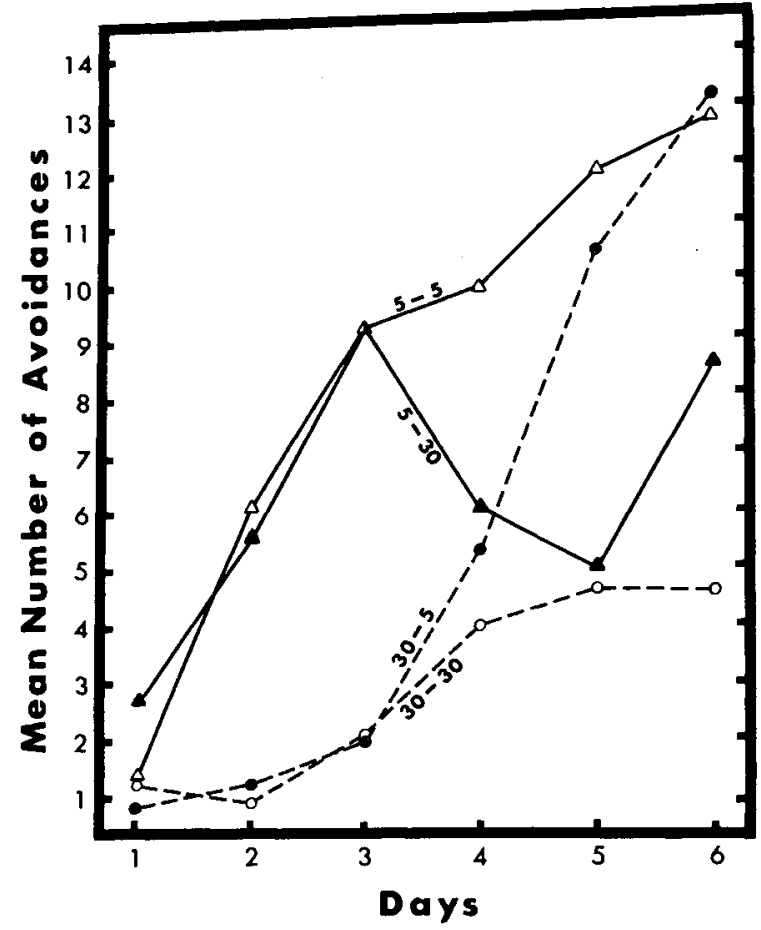

Fig. 1. Mean number of avoidances made by each of the four groups over the six days of the experiment. 


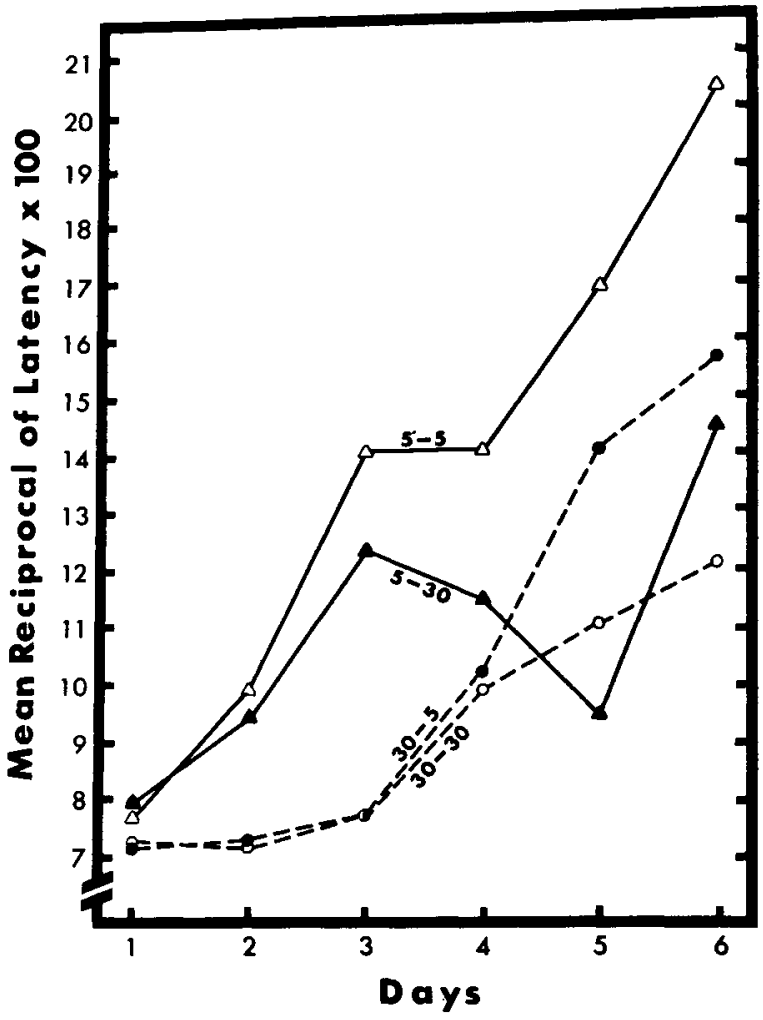

Fig. 2. Mean reciprocal of Iatency $(1 / t \times 100)$ for each of the four groups over the six days of the experiment.

avoidances than the two groups trained with the $30 \mathrm{sec}$ ITI on Day $2(t=4.10, d f=54, p<.001)$, and Day 3 $(t=4.52, d f=54, p<.001)$. Following the shift, the performance of Group 5-30 dropped until Day 5, where it differed significantly from Group 5-5 $(t=2.62$, df $=26, \mathrm{p}<.02)$. The performance of Group 30-5, meanwhile, improved to the point that it differed significantly from Group $30-30$ on Day $5(t=2.37, \mathrm{df}=26$, $p<.05)$ and Day $6(t=3.22, d f=26, p<.01)$.

The latencies of response for each of the four groups were converted to reciprocals $(1 / \mathrm{t} \times 100)$. Their means are shown in Fig. 2. These data were also subjected to an analysis of variance, with the main effects of shift $(F=99.78, d f=1 / 156, p<.001)$, days $(\mathrm{F}=27.27, \mathrm{df}=2 / 104, \mathrm{p}<.001)$, and groups $(\mathrm{F}=\mathbf{2 . 8 7}$, $\mathrm{df}=3 / 52, \mathrm{p}<.05$ ) all significant. All interactions, except shift by days by groups, were also significant. Discussion

The results of this study confirm the findings of Murphy \& Miller (1956), Brush (1962), and Pinckney (1966), and others, that Ss trained with longer ITIs make significantly more avoidances in shuttlebox avoidance learning.

The data, however, do not support the distribution of practice or the incentive hypothesis concerning the effect of length of ITI on avoidance learning. The distribution of practice hypothesis would suggest that shifting from a short ITI to a long one would constitute a change from massed to spaced conditions. and should therefore lead to enhanced performance. Conversely, shifting from a long ITI to a short one would constitute a change from spaced to massed practice, and should lead to a decrement in performance. The performance of Group 30-5 supports this position, but the performance of Group 5-30 does not. The decrement produced by the shift from spaced to massed conditions would be a permanent one. The recovery of Group 5-30 from Day 5 to Day 6 is contrary to this explanation. The incentive hypothesis would offer the same suggestions on performance change as the distribution of practice hypothesis, and is therefore equally untenable.

The performance of Ss following the shift in ITI might be explained by the generalization decrement hypothesis. Since the ITI is an important part of the total stimulus complex, any change in its length might be expected to lead to a temporary decrement in performance. Group 5-30 was trained with a relatively long ITI for the first three days, and proprioceptive cues associated with this interval would be severely affected by the shift to the short ITI. As a result, avoidance behavior of this group should be severely disrupted. Figs. 1 and 2 show this to be the case. Group 30-5, however, had been trained with a short ITI for the first three days, and proprioceptive cues associated with the $30 \mathrm{sec}$ interval should not be affected, to any great extent, by the shift to the longer interval. Support for this point should come from intertrial response data, since Group 30-5 would be expected to show an increase in this behavior following the shift. Unfortunately, such data were not recorded.

\section{References}

Brush, F. R. The effects of intertrial interval on avoidance learning in the rat. J. comp. physiol. Psychol., 1962, 55, 888-892.

Crespi, L. P. Amount of reinforcement and level of performance. Psychol. Rev., 1944, 51, 341-357.

Murphy, J. V., \& Miller, R. E. Spaced and massed practice with a methodological consideration of avoidance conditioning. $J$. exp. Psychol., 1956, 52, 77-81.

Pinckney, G. A. The effect of intertrial interval on avoidance learning in fish. Psychon. Sci., 1966, 6, 497-498.

Zeaman, D. Response latency as a function of amount of reinforcement. J. c.rp. Psychol., 1949, 39,466-483.

\section{Notes}

1. Portions of this report were presented at the annual meeting of Eastern Psychological Assuciation, Boston, April, 1967.

2. This research was supported by Grant 22-11-A from the Research Foundation of State University of New York. 